CRÍTICA, Revista Hispanoamericana de Filosofía

Vol. XXXI, No. 91 (abril 1999): 75-90

INTERROGATIVES AND SETS OF ANSWERS

ROBERT J. STAinton

Carleton University

In what follows, I introduce and then criticize a recently popular approach to the semantics of interrogatives. According to what I will call the "set-of-answers" strategy, an interrogative denotes a question, where a question just is a set of answers. This is the approach I will argue against.

My preference is for a more traditional story - the "force and radical" approach- according to which interrogatives are composed of a sentence radical and a force indicator. The force indicator contributes interrogatival force to the sentence type, while the radical, given a context, denotes either a proposition, or a propositional function - depending upon whether the sentence is a yes-no or wh- interrogative. (E.g. the radical of 'Is it raining?' denotes the proposition that it is raining; the radical of "Which man invented the hot dog?' has a denotation something like $[\lambda x \cdot \operatorname{man}(x): x$ invented the hot dog].)

I won't be defending the traditional approach here. But to clarify the comparison between my favored approach and the view I'll argue against, I should say a bit about the former. I assume that sentence radicals are assigned meanings in the usual compositional way: There must be base axioms which assign meanings to parts, and recursive axioms which determine whole-meanings on the basis of part-meanings and syntax. In particular, I assume that, 
given a context, individuals are assigned to singular terms, propositional functions to predicates, and propositions to declarative sentences.

This much is shared with the set-of-answers approach. But what about force indicators? For present purposes, I'll suppose that the force of a sentence type is determined by what force an utterance of the expression will have ceteris paribus. Thus the sentence type 'Is it raining' has interrogatival force in the sense that, absent any defeating factors that might indicate non-standard usage, tokens of it will be askings. I take it that there are a quite limited number of forces - e.g. used to ask, used to assert, used to order and possibly a couple more. As a result, forces do not have to be assigned compositionally, at least not in the usual way. Rather, all that is required is for the grammar to recognize some global feature of whole sentences, assigning each sentence to one of the three or four classes on these grounds. ${ }^{l}$ (Obviously the global features will have to be such that embedded sentences don't exhibit them. This can be achieved most easily by stipulating that only matrix sentence types count. But I'll say more about embedded interrogatives below.)

I should also note that the introduction of something like forces is motivated on independent grounds. There are, I take it, expressions for which, to speak loosely, the right meaning theory is essentially a "use theory": e.g. phatics

1 It's not even necessary, as is often assumed, that there be a single syntactic indicator of force: e.g. a Q morpheme. There may be such a thing - indeed, in some languages it's pretty clear that there is. But there could also be languages in which there were, say, five different global features of sentences, any one of which was sufficient for assigning interrogatival force. Thus one might say that, in English, sentence types with at least one of (a) rising intonation; (b) AUX moved into initial complementiser position; or (c) appropriate $d o$-insertion has interrogatival force. (Of course this will at best account for yes-no interrogatives in English.) 
like 'Hello' and 'Cheers'. To give the meaning of 'Hello' involves no more than giving the rules for its use: "Used to greet someone" and so on. A statement of reference or sense for 'Hello' is clearly out of place. (Similarly, at this stage of English usage, for 'Cheers' as used in bars.) Now this sort of use theory -impoverished as it may be at assigning unlimited numbers of meanings to sentences, on the basis of what their parts mean and how the parts fit together - can be applied not only to phatics but also to force indicators. With this difference: a traditional compositional-referential theory also applies to whole sentences, whereas it doesn't apply at all to phatics. As a result, whole sentences get assigned two kinds of "meaning", each independently required: reference (via the compositional mechanism) and use (determined by "global features" like word order, intonation, etc. See note 1).

To repeat, it will not be my task to defend this traditional approach. Rather, my aim is wholly negative: to raise some concerns about a newfangled alternative. I turn to that now.

\section{The Set-of-Answers Proposal}

Let me begin with a terminological warning. To understand the set-of-answers approach, it's important to distinguish interrogatives (which are linguistic expressions) and askings (which are actions) from questions. Only the last are claimed to be the contents of interrogatives. (Compare sentences, assertions and propositions.) It is questions, rather than interrogatives or askings, that are to be equated with sets of answers; and it is questions which, on this story, are denoted by interrogative sentences. It is equally important to distinguish mere responses to an interrogative on the one hand, from answers to it on the other. Saying 'I don't know' or 'No hablo inglés' count as responding to (1).

1. Which man invented the hot dog? 
But the propositions I DON'T KNOW and I DON'T SPEAK ENGLISH are not answers to (1), in the intended sense. It is answers in a restricted, about-to-be-explained sense which, jointly, constitute a question - and, according to the setof-answers strategy, therefore constitute the content of interrogatives.

So, what is an answer? There are at least three options. ${ }^{2}$ (I will introduce each because I want it to be clear that my objection is not specific to any one set-of-answers theory.) For Karttunen (1977), an answer to (1) is any true proposition expressed by a sentence of type (2), where $X$ may be replaced by either a name or a quantifier phrase.

2. $\left\ulcorner X\right.$ invented the hot $\operatorname{dog}^{\urcorner}$

So, for example, if Henry Frankfurt alone invented the hot $\mathrm{dog}$, then the answer to (1), for Karttunen, is the proposition that HENRY FRANKFURT INVENTED THE HOT DOG. Other replies, or responses, even if they mollify the questioner, are not answers. The question corresponding to "Which man invented the hot dog' is, on this variant, the set of true answers. In this scenario, the unit set:

3. \{HENRY FRANKFURT INVENTED THE HOT DOG

On the other hand, if both Henry Frankfurt and Bill Clinton invented the hot dog, then both (4) and (5) are answers to (1), according to Karttunen. Hence the question denoted by (1) is, for him, the set in (6).

2 Variations on this theme can be found, among other places, in Groenendijk and Stokhof (1989), Hambling (1973), Higginbotham (1991), (1993), Higginbotham and May (1981), Karttunen (1977) and Lahiri (1992). In what follows, I abstract away from the subtleties of the various proposals, and gloss over the debates between members of this set-of-propositions camp. My aim here is not, after all, exegesis. Rather, I intend to provide a rough-and-ready familiarity with the general features of the proposal. It is, I think, these general features that lead to trouble. 
4. \{HENRY FRANKFURT INVENTED THE HOT DOG

5. $\{$ BILL CLINTON INVENTED THE HOT DOG $\}$

6. \{HENRY FRANKFURT INVENTED THE HOT DOG, BILL CLINTON INVENTED THE HOT DOG

This is one account of what an answer is. Another account, again illustrated using sentence (1), is suggested by Hamblin (1973). On this variant, an answer to (1) is any proposition expressed by a sentence of type (2), whether or not it is true. Where both Henry F. and Bill C. invented the hot dog, for example, Karttunen and Hamblin agree on which propositions answer (1): (4) and (5) do. Hence they agree on what question is denoted by (1) - namely the set of propositions in (6). However, in a situation in which Henry Frankfurt alone invented the hot dog, this second Hamblin-inspired variant would nevertheless count both (4) and (5) as answers, even though only (4) is true. Hence, on this second version, where the domain of inventor-candidates contains exactly two members, Henry F. and Bill C., (6) is always the question denoted by (1), regardless of who did the actual inventing.

Higginbotham (1993), building on Higginbotham and May (1981), offers a third variation on the set-of-answers theme. According to Higginbotham, an interrogative does denote a set of answers. But, for him, an answer is more than a single proposition - e.g. a proposition expressed by a sentence of type (2). Karttunen, recall, takes an answer to be a true proposition of a certain form; Hamblin also counts, as an answer, any false proposition of this same form. Notice that each author has an answer being $a$ single proposition, so that an interrogative denotes a set of propositions. Higginbotham maintains that this misses a distinction between complete answers and merely partial answers. According to him, a complete answer to (1) must convey more information than which individuals did in- 
vent the hot dog; it must also say, of everyone who did not invent the hot $\mathrm{dog}$, that they failed to do so. Hence, in a domain with exactly two agents, Bill Clinton and Henry Frankfurt, a complete answer to (1) would never be, for Higginbotham, simply HENRY FRANKFURT INVENTED THE HOT DOG but rather \{HENRY FRANKFURT INVENTED THE HOT DOG=TRUE, BILL CLINTON INVENTED THE HOT DOG=FALSE $\}$.

In the general case, where the domain contains $N$ agents, Higginbotham's account would entail that a complete answer to (1) look like (7):

7. AGENT $_{1}$ INVENTED THE HOT DOG=TRUE, AGENT 2 INVENTED THE HOT DOG=FALSE, AGENT 3 INVENTED THE HOT DOG=

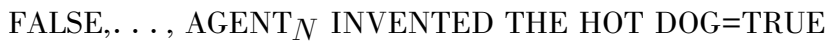

Call a cell an assignment of truth values to the minimal propositions of the appropriate form. For instance, where $P$ is a property, $x_{n}$ are individuals, and $t$ is a variable over truth values, the diagram in (8) is a cell-schema:

8. $P\left(x_{1}\right)=t$

$$
\begin{aligned}
& P\left(x_{2}\right)=t \\
& \cdot \\
& P\left(x_{n}\right)=t
\end{aligned}
$$

According to Higginbotham, each cell is a complete answer; and the set of these cells is what interrogatives denote. For example, returning to (1), and retaining the assumption of a two-person domain, one has the following complete answers (i.e. cells):

9. \{HENRY FRANKFURT INVENTED THE HOT DOG=TRUE, BILL CLINTON INVENTED THE HOT DOG=TRUE $\}$

10. $\{$ HENRY FRANKFURT INVENTED THE HOT DOG=TRUE, BILL CLINTON INVENTED THE HOT DOG=FALSE $\}$ 
11. \{HENRY FRANKFURT INVENTED THE HOT DOG=FALSE, BILL CLINTON INVENTED THE HOT DOG=TRUE $\}$

12. $\{$ HENRY FRANKFURT INVENTED THE HOT DOG=FALSE, BILL CLINTON INVENTED THE HOT DOG=FALSE $\}$

As Higginbotham (1993, p. 196) says, a set of cells such that (a) no more than one cell corresponds to the true state of nature and (b) at least one cell must correspond to the true state of nature, is a partition. One may thus sum up his view as follows: Interrogative sentences denote partitions. (Hence (1) corresponds to the partition whose member-cells are (9) through (12).)

Before considering the merits and weaknesses of this approach, a brief digression is in order. You might be wondering what the set-of-answers approach says about yes-no interrogatives. The general approach is the same. Yes-no interrogatives denote questions, where questions are sets of answers. In this case, however, the sets are more straightforward. On the first variant, due to Karttunen, the answer to (13) is one of (14) or (15), whichever is true.

13. Is it raining?

14. IT IS RAINING

15. IT IS NOT RAINING

On the second variant, due to Hamblin, both (14) and (15) count as answers, regardless of which is true. Hence the question denoted by (13) is either the unit set containing one of (14) or (15) (on the Karttunen variant); or it is the set containing both (in the Hamblin variant). The third variant, that of Higginbotham, departs from the second only in taking the question to be a set of unit sets: $\{\{$ IT IS RAINING $\},\{$ IT IS NOT RAINING $\}$. 


\section{Problems with the Proposal}

I hope I've said enough to give the flavor of this approach. I now want to raise two problems with it. I will not try to offer knock down arguments.

\section{Whence Standard Use?}

It's an important fact - a fact central to their very naturethat interrogative sentences are typically used to ask. This is not, I take it, an epiphenomenon of language use. (Compare the unsurprising fact that oft-used verbs - e.g. 'To be'- tend to have irregular conjugations.) Instead, this fact derives somehow from the meaning of interrogatives. Now consider: How does the set-of-answers proposal explain the use of interrogatives? Here's a first guess: The kind of object which interrogatives are said to denote - namely, sets of answers - somehow "correlates with" the act of asking. The idea would be that, in virtue of denoting this kind of (rather complex) object, utterances of interrogative sentences are able to exhibit a different standard use than, say, utterances of declarative sentences.

This first guess is initially plausible, but ultimately unsatisfying - because there are phrases which share this denotation type, but lack the standard use. Take (16), (17) and (18).

16. That unique set whose sole member is IT IS NOT RAINING

17. That unique set whose members are IT IS RAINING and IT IS NOT RAINING

18. That unique set whose members are the unit sets $\{$ IT IS RAINING and IT IS NOT RAINING

The noun phrases in (16), (17) and (18) each denote a set. (Notice: I specifically do not use a definite description, to make it clear that these are referential and not quantifi- 
cational expressions.) Indeed, each denotes the very same set as (13), 'Is it raining?' - according to the first, second and third variants of the set-of-answers story, respectively. And yet, whereas (13) is typically used to ask, (16), (17) and (18) are not. Why is this? Not because phrases can never be used on their own. As I have argued elsewhere, in Stainton (1994, 1995), words and phrases can be, and often are, used outside any sentence: E.g., one can begin a conversation with 'Hungry?', or 'A friend of yours?' Nor, it seems to me, is it because the content of (13) is too difficult to understand, when couched in these substantival terms: It's not as if these noun phrases are so much more difficult to parse than the corresponding interrogative sentence. Rather, sentence (13) is understood as having a typical use which (16), (17) and (18) lack because sentence (13) has interrogatival force as part of its content, whereas none of (16), (17) or (18) do. This difference between (13) on the one hand, and (16) through (18) on the other, is not captured by any of the foregoing variants on the set-ofanswers approach. But it is captured by a more traditional force and radical story, of the kind proposed by Davidson (1979), Dummett (1973), Frege (1918), McGinn (1977), and Segal (1991), among others.

What's more, there's an overarching reason for thinking that the nature of the object denoted could not determine that, for example, the expression is used to ask: If there were such "inherently interrogatival objects", we could not speak of them without attempting to ask a question! Any reference to such an object would, by definition, be interrogatival. Hence saying something about such objects would not be possible. Indeed, if the alleged object which gives (1) its use exists, then the phrase 'that alleged object which gives (1) its use' refers to this object. In which case, this latter phrase should also be used to ask... and my last full sentence, in using this phrase, should have been 
interrogatival in force. This is clearly absurd. I conclude that there is no way in which the kind of object denoted could, in and of itself, determine the use of the denoting expression.

A possible reply. As Frege noted long ago, there is a difference between the expressions in (19) and (20).

19. It is raining

20. That unique proposition which is true iff it is raining here and now

Frege locates the difference in this: (19) expresses what (20) designates. Put otherwise, the sense of (19) is the referent of (20). One might suggest, then, that the reason why (13) is standardly used to ask - whereas, for instance, (17) is not - is that (13) expresses a set-of-answers, whereas (17) denotes a set-of-answers. In other words, the simple semantics that I have been assuming is too simple, because it pretends that the only semantic relation is denotation. The solution to this puzzle about standard use, goes the reply, is to eschew the pretense, and distinguish denotation and sense. (Higginbotham (1993, pp. 213-217), repairing an omission in Higginbotham and May (1981), suggests a solution along these lines.)

But this just pushes the question back a step. It remains a mystery why the relation express::denote should parallel the relation having-force::lacking force. As I see it, the set-of-answers theorist faces a dilemma. Either he can provide no explanation of why expressing a question should correlate with asking; or he can do so only by explicitly including something about use/force within his theory of sense. ${ }^{3}$ Were the set-of-answers theorist to do the latter,

3 Dummett's work illustrates the fact that one can explain why "expressing" and force go hand in hand. But, notoriously, Dummett (1973) does not replace force with something else. Also, as James 
however, his view would cease to be an alternative to the traditional one, and would instead become a rather complex version of it. Besides, given the well warranted move away from intensionalism in semantics, is it worth bucking the extensionalist trend on these grounds, given the rather happy alternative of using the independently necessitated notion of standard uses? I think not. I conclude, then, that the set-of-answers story, understood as a genuine alternative to the traditional view, lacks a motivated account of why interrogatives are typically used to ask. Since, as I said at the outset of this section, I take this property to derive from the meaning of interrogatives, I conclude that this approach gets the semantics wrong. This suggests that, at best, the set-of-answers story captures only the propositional part of which-interrogatives. A theory of force is still required. However, as I'll now argue, even on the score of propositional content, the set-of-answers account does no better than the traditional force and radical theory.

\section{Constructing Questions}

There is, it seems to me, an important sense in which the set-of-answers account of interrogatives can be derived from (the sentence radical side of) the force and radical approach. I will illustrate this point with the most complex case: Higginbotham's variant. Here is the idea. Given the domain of the interrogative -i.e. the individuals who

Higginbotham kindly pointed out to me in conversation, the set-ofanswers proponent has a special burden that Dummett did not face. That's because the former cannot say that what is special about usemeanings is that they attach to things which denote a truth value. After all, interrogatives on this theory do not denote truth values. Hence the set-of-answers theorist must explain why, whereas not all phrases which "express" have use-meanings (e.g. names and predicates don't), interrogatives do have this kind of meaning. 
are candidate $\theta$-ers, for the given property $\theta$ - and a sentence radical (i.e. a lambda abstract), one can derive the corresponding partition. Therefore, whatever can be done in (the most powerful of) the set-of-answers theories must be do-able given a sentence radical and a domain, since the former can be got from the latter. Hence introducing setsof-answers provides nothing extra, beyond what supplying the domain of the interrogative would provide.

Here is a very informal derivation.

1. Let $\mathbf{P}(\mathrm{D})$ be the power set of $\mathrm{D}$, where $\mathrm{D}$ is the domain of the interrogative.

2. For each set $\mathrm{S}_{i} \in \mathbf{P}(\mathrm{D})$, let $\mathrm{S}_{i}{ }^{*}$ be the set of objects in $\mathrm{D}$, but not in $\mathrm{S}_{i}$.

3. For each set $S_{i} \in \mathbf{P}(D)$, we form the set of propositions $A_{i}$, whose members result from predicating the sentence radical (i.e. lambda abstract) of the interrogative of each member of $S_{i}$. Similarly, we form the set of propositions $\mathrm{N}_{i}$ whose members result from predicating the lambda abstract of each member of $\mathrm{S}_{i}{ }^{*}$, and then negating this proposition.

4. For each set of propositions $\mathrm{A}_{i}$ and $\mathrm{N}_{i}$ we form the union set $\mathrm{C}_{i}$.

5. Finally, we form the set of all sets $C_{i}$. Each $C_{i}$ will be a cell of a partition. The partition itself will correspond to the interrogative, given domain D.

And here is an example. Let the domain D of candidateinventors be $h$ and $b$. Then:

1. $\mathbf{P}(\mathrm{D})$ is $\left\{\{h\},\{h, b\},\{b\},\left\{\_\right\}\right\}$

2. $\mathrm{S}_{1}=\{h\}, \mathrm{S}_{2}=\{h, b\}, \mathrm{S}_{3}=\{b\}, \mathrm{S}_{4}=\left\{\_\right\} ;$and $\mathrm{S}_{1} *=\{b\}$, $\mathrm{S}_{2}{ }^{*}=\left\{\_\right\}, \mathrm{S}_{3} *=\{h\}, \mathrm{S}_{4}^{*}=\{h, b\}$. 
Let the sentence radical be ( $\lambda x . x$ invented the hot dog). In which case,

3. $A_{1}=\{h$ INVEnTED THE HOT Dog $\}, A_{2}=\{h$ INVENTED THE HOT DOG, $b$ INVENTED THE HOT DOG $\}, A_{3}=\{b$ INVENTED THE HOT DOG $\}, \mathrm{A}_{4}=\{\ldots\}$; and $\mathrm{N}_{1}=\{b$ DID NOT INVENT THE HOT DOG $\}, \mathrm{N}_{2}=\left\{\_\right\}, \mathrm{N}_{3}=\{h$ DID NOT INVENT THE HOT DOG $\}$, $\mathrm{N}_{4}=\{h$ DID NOT INVENT THE HOT DOG, $b$ DID NOT INVENT THE HOT DOG $\}$

From these, by set union, we form the cells $\mathrm{C}_{1}$ through $\mathrm{C}_{4}$ :

4. $\mathrm{C}_{1}=\{h$ INVENTED THE HOT DOG, $b$ DID NOT INVENT THE HOT DOG $\}, \mathrm{C}_{2}=\{h$ INVENTED THE HOT DOG, $b$ INVENTED THE HOT DOG $\}, \mathrm{C}_{3}=\{b$ INVENTED THE HOT DOG, $h$ DID NOT INVENT THE HOT DOG $\}, \mathrm{C}_{4}=\{h$ DID NOT INVENT THE HOT DOG, $b$ DID NOT INVENT THE HOT DOG $\}$

The partition corresponding to "Which man invented the hot dog' is then the set of the above cells.

If I am right that a set-of-answers can be derived; and that, therefore, the set-of-answers approach can do no more that the traditional view, does this make the two approaches equivalent? Absolutely not. Not only because the traditional view is thicker - it assigns forces to interrogative sentences - but also because the traditional view is thinner: It does not make the domain of an interrogative part of its meaning. The propositional content of a whichinterrogative is, on the force and radical approach, completely exhausted by the lambda abstract. (Though one can specify a domain, and thereby derive the set of answers.) This difference favors the traditional approach, in my view, because one can understand an interrogative perfectly well, without knowing precisely what its domain is.

Notice, by the way, that it's important for the traditional view that it can achieve everything that the set-of-answers 
theory can, because the latter applies to embedded interrogatives in a straightforward way. Indeed, the set-of-answers approach was specifically designed to apply to embedded, rather than to matrix, interrogatives - and it works rather well for those cases. On the other hand, it's always been a concern that the traditional view, however well it worked for unembedded cases, had nothing useful to say about sentences like the following:

21. John wondered who invented the hot dog

22. Maria asked whether it was raining

If, however, the set-of-answers view can be derived from the sentence-radical part of the traditional view, then in so far as the former accounts for so-called indirect questions, the latter must as well.

In sum, the set-of-answers approach to interrogatives is no better than the more traditional force and radical approach: everything that can be done using the former can be done using the latter. Moreover, the set-of-answers approach faces difficulties not faced by the force and radical theory: In particular, it does not explain the typical use of interrogatives, and it inappropriately builds the domain of the interrogative into its meaning. I therefore conclude that the traditional approach is preferable. ${ }^{4}$

4 The groundwork for the views presented here was laid during a Summer seminar I gave at the Instituto de Investigaciones Filosóficas a few years back. Versions of the paper, in more or less its present form, were then read at Concordia University in Montreal and at the 1998 meetings of the Southern Society of Philosophy and Psychology in New Orleans. I'm very grateful to those present on these diverse occasions for useful feedback. Thanks also to Sylvain Bromberger and James Higginbotham for many hours spent discussing interrogatives. (Of course they likely will not agree with what I've written.) Finally, I'm grateful to Paul Pietroski, both for discussion of these issues and for encouraging me to publish my ideas. 


\section{REFERENCES}

Davidson, D., 1979, “Moods and Performances", reprinted in Davidson (1984), Inquiries into Truth and Interpretation, Clarendon Press, Oxford.

Dummett, M., 1973, Frege: Philosophy of Language, Duckworth, London.

Frege, G., 1918, "The Thought", reprinted in P.F. Strawson (ed.) (1967), Philosophical Logic, Oxford University Press, Oxford.

Groenendijk, J. and M. Stokhof, 1989, "Type-Shifting Rules and the Semantics of Interrogatives", in G. Chierchia et al. (eds.), Properties, Types, and Meaning, volume 2, Kluwer, Dordrecht.

Hamblin, C., 1973, "Questions in Montague English", Foundations of Language, 10, pp. 41-53.

Higginbotham, J., 1993, "Interrogatives", in K. Hale and J. Keyser (eds.), The View from Building 20: Essays in Linguistics in Honor of Sylvain Bromberger, The MIT Press, Cambridge.

—_, 1991, "Interrogatives I", MIT Working Papers in Linguistics, 15, pp. 47-76.

- and R. May, 1981, "Questions, Quantifiers and Crossing", The Linguistic Review, 1, pp. 41-80.

Karttunen, L., 1977, "The Syntax and Semantics of Questions", Linguistics and Philosophy, 1, pp. 3-44.

Lahiri, U., 1992, "Embedded Interrogatives and the Predicates that Embed Them", unpublished Ph.D. dissertation, Department of Linguistics and Philosophy, Massachusetts Institute of Technology.

McGinn, C., 1977, "Semantics for Nonindicative Sentences", Philosophical Studies, 32, pp. 301-311.

Segal, G., 1991, "In the Mood for a Semantic Theory", Proceedings of the Aristotelian Society, 91, pp. 103-118. 
Stainton, R.J., 1995, “Non-Sentential Assertions and Semantic Ellipsis", Linguistics and Philosophy, 18, pp. 281-296.

_ Theory", Pragmatics \& Cognition, 2, pp. 269-284.

Recibido: 12 de febrero de 1999 